\title{
A NEW METHOD FOR IN-SITU MEASUREMENT OF THE EROSION THRESHOLD OF RIVER CHANNELS
}

\author{
PREPRINT, COMPILED JUNE 5, 2019
}

\author{
Kieran B.J. Dunne ${ }^{1 *}$, Paulo E. Arratia ${ }^{2}$, and Douglas J. Jerolmack ${ }^{1,2}$ \\ ${ }^{1}$ Department of Earth \& Environmental Science, University of Pennsylvania, Philadelphia, Pennsylvania, USA \\ ${ }^{2}$ Department of Mechanical Engineering \& Applied Mechanics, University of Pennsylvania, Philadelphia, Pennsylvania, USA
}

\begin{abstract}
The vast majority of alluvial deposits have some degree of cohesion, typically due to the presence of clays and/or organic matter. Determining the threshold fluid shear stress, $\tau_{c}$, necessary to entrain these sediments is essential for predicting erosion rates and morphodynamics of rivers, tidal channels, and coasts. Cohesive sediments present a greater challenge than non-cohesive sand and gravel beds due to the sensitivity of $\tau_{c}$ to such factors as compaction, aggregation and particle surface chemistry. All of those factors may be altered if bed and bank sediments are extracted for later analysis in the laboratory. Environments with mixed cohesive and non-cohesive materials are common, such as sand-bedded rivers with muddy banks; it is therefore desirable to have a method for in-situ measurement of $\tau_{c}$ across a very wide range. We present a novel instrument, provisionally called the "Mudbuster", that is capable of reproducibly determining $\tau_{c}$ for submerged cohesive and non-cohesive sediments in-situ. The Mudbuster has several advantages over alternative methods, including ease of implementation in the field, and a fluid shear that is more representative of natural flows. The device incorporates common and low-cost components integrated with an Arduino micro-controller, which may receive commands from a mobile phone. We demonstrate our instrument's capabilities in gravel, sand, and clay-sand mixtures prepared in the laboratory, and present a proof-of-concept field deployment in a wadeable stream. Additionally, we provide the necessary schematics, parts lists, code, and calibration procedures for the interested reader to build their own Mudbuster.
\end{abstract}

\section{INTRODUCTION}

Cohesive sediment covers an overwhelming majority of the Earth's surface [1, 2, 3, 4]. We consider cohesion to be any kind of inter-particle attraction beyond contact friction; in natural sediments, cohesion is associated with fine particulates like clays and organic matter, where surface area to volume ratios become large $[5,6,7]$. While muddy landscapes may be entirely composed of cohesive particles (silt and finer), even small amounts of clay may increase the bulk strength of otherwise non-cohesive sand [6, 7]. Water currents and waves impinging on these materials impose a boundary shear stress $\tau_{b}$ that sculpts terrestrial and submarine landforms such as rivers, tidal channels, marsh platforms and undersea channels. Determination of the threshold shear stress for entrainment, $\tau_{c}$, is necessary for predicting the onset of erosion, and also for determining sediment transport rates that are typically cast as a function of excess shear stress, $q_{s} \propto\left(\tau_{b}-\tau_{c}\right)[8,9,10,11,12]$. Moreover, studies in non-cohesive $[13,14,15]$ and cohesive $[16,17]$ sediments have demonstrated the strong influence $\tau_{c}$ exerts on landscape morphology; for example, the organization of river channel geometry such that the formative boundary stress is close to $\tau_{c}[13,14]$. For decades, the state of the art for predicting $\tau_{c}$ for non-cohesive sediments has been the Shields curve, which casts the entrainment threshold as a balance between near-bed fluid forces and particle friction [18]. More recent studies have demonstrated the modulating effects of fluid turbulence [19, 20, 21, 22], grain protrusion [23, 24] and bed compaction [25, 26] on $\tau_{c}$. For cohesive sediments involving fine-grained (silt and smaller) particles, additional forces such as electrostatics and van der Waals [5] must be considered. The latter are quite sensitive to water chemistry (e.g., salinity and $\mathrm{pH}$ ), history of compaction, and material composition (e.g., clay mineralogy) [27, 28, 17, 29], which have been shown to influence river-bank erosion rates through their effect on $\tau_{c}[30,31]$. With this wide range of confounding variables, which may also be time dependent, theoretical predictions of $\tau_{c}$ for cohesive materials are of limited use for natural landscapes. Site-specific correlations between $\tau_{c}$ and clay/silt content have been developed for some rivers [7], but they cannot be generalized to other settings.

In light of these challenges, much attention has been focused on methods to empirically determine $\tau_{c}$ for cohesive sediment in the field $[16,32,33,34,35]$. Our own previous research suggested that variations in $\tau_{c}$ between the bed and banks of a river may exert a strong control on the shape of river channels [36], and we emphasized the need for in-situ determination of $\tau_{c}$ at the toe of river banks. Accordingly, we seek a method capable of measuring the submerged threshold entrainment stress of cohesive

\footnotetext{
*dengjiamin@gmail.com
} 
and noncohesive materials typically encountered in rivers, estuaries and marshes; and this method must be spatially localized, to allow examination of variation along a channel cross section. We briefly survey existing methods below and find that they are either too unwieldy, or too damaging to the substrate, to be reliable. We then report a novel instrument that we have developed for the purpose of measuring in-situ $\tau_{c}$ that emphasizes portability, affordability, and comparability to natural methods of sediment entrainment. We provisionally call this device the "Mudbuster". We show that the Mudbuster can reproducibly determine the threshold entrainment stress for particles ranging from clay to gravel, and we offer a blueprint for others to construct and test their own Mudbuster. Our hope is that researchers and practitioners will adopt and improve on our design, and that this will facilitate the widespread measuring and reporting of $\tau_{c}$ in various cohesive sediment environments. Such measurements will aid in the design and restoration of cohesive sediment landscapes (e.g., river restoration), and also lead to a better understanding of environmental controls on the entrainment threshold itself. Our current instrument design limits deployment to shallow water (i.e, wadeable) environments; however, the technique could be easily adapted to be deployed in deeper water environments by divers or by mounting on submersibles.

\section{Existing Methodologies}

As mentioned above, numerous methods have been developed to test the erodibility of cohesive sediments (Fig. 1). The commonality between these multiple methods is that they all have a way of controlling the shear stress applied to a substrate.

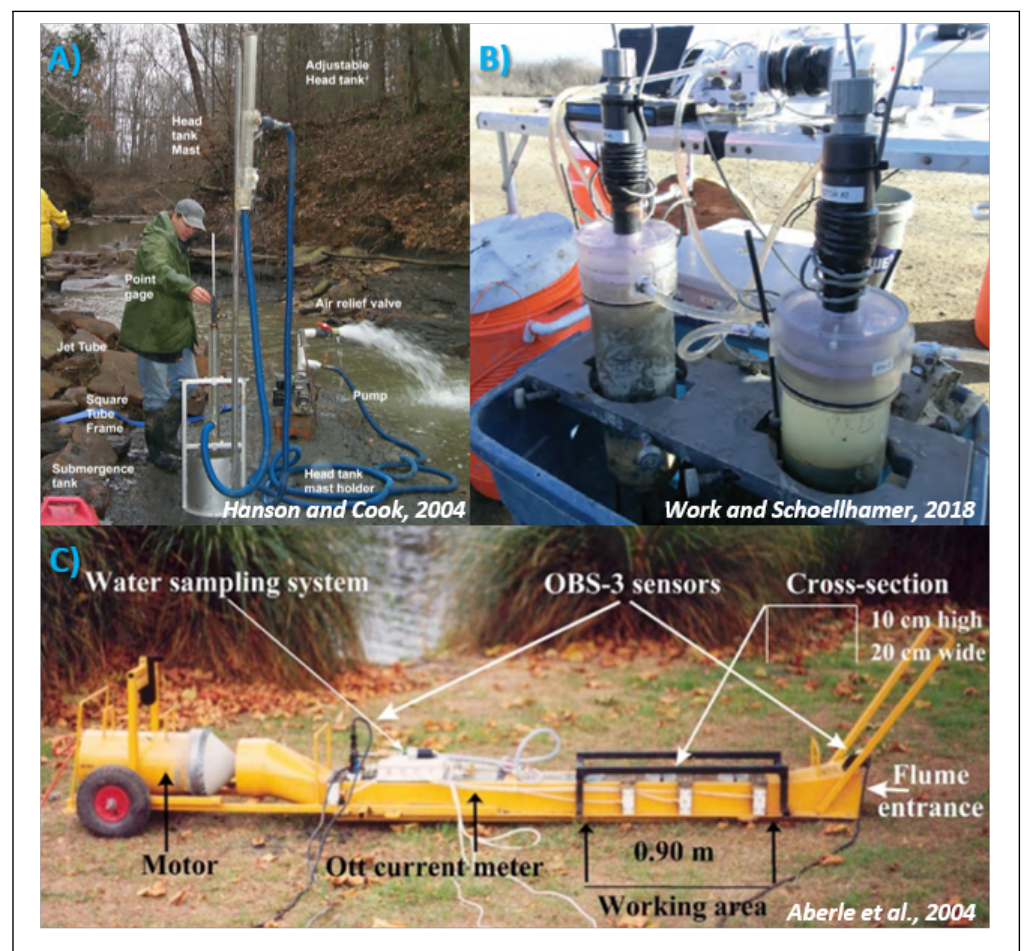

Figure 1: A) Jet tester being deployed in a field setting [32]; B) Field-deployable flume [34]; C) Gust chamber setup [37]

The most common method to test the erodibility of cohesive sediments is through the use of a jet tester, which has been employed on a variety of substrates and environments $[16,32,33]$. The jet tester utilizes an impinging jet, normal to the surface of interest, to scour the substrate (Fig. 1A). The scour depth is calculated using a point gage, and $\tau_{c}$ of the substrate is back-calculated from the depth of the scour relative to the force of the impinging jet. Despite its prevalence, the primary weakness of the jet tester method is that it does not provide a method of erosion that is kinematically-comparable to the method of erosion naturally experienced by sediment. An impinging jet is kinematically different to a normal flow in that the jet tester produces a primarily extensional/contractile flow with little vorticity, while a normal flow is a vorticity-dominant, simple shear flow. Furthermore, the jet test is subject to a wide range of error associated with the method of inducing erosion [38]. For all these reasons, it is difficult to extrapolate a meaningful and useful value from the result produced by the jet tester if the goal is to use that value to understand the erodibility of sediment in response to a horizontally applied fluid shear opposed to an impinging jet.

Numerous field studies have implemented flumes in the field, in both fluvial and marine environments, to induce sediment transport in a comparable manner to how sediment is transported both in laboratory and natural settings (Fig. 1B). While these flumes vary in size and shape, the common principle for their use is to impose a horizontally applied fluid shear stress using flow through an open-bottom flume placed on top of the substrate of interest. $\tau_{c}$ for the substrate is determined by monitoring abrupt changes in the turbidity of the water flowing through the flume, and contrasting those observed changes against the measured shear stress, 
calculated from the velocity profile of the flow [34, 35, 39]. While this method is undeniably effective, it is both cumbersome and expensive. Maneuverability in field environments can be a critical asset for an erodibility testing device to allow for the targeting of either specific morphological features of interest, such as bank toes, or avoiding undesirable environmental complexities, such as tree roots or overly-large cobbles. As field flumes have been primarily deployed in topographically simple environments, such as tidal flats and river beds, maneuverability is not of first-order concern [34, 39]. However, for studies that require the targeting of more morphologically complex features for erodibility testing, maneuverability is of paramount concern.

The method that perhaps best combines an application of shear stress to a substrate that is comparable with the shear stress exerted by a gravity-driven flow in a channel, with the potential for portability in a field setting is the Gust Chamber [40, 41]. The Gust Chamber utilizes a rotating flat plate to shear a column of water in a chamber, which in turn exerts a horizontal fluid shear stress on the sediment at the bottom of the chamber (Fig. 1C). $\tau_{c}$ for the substrate is determined by monitoring changes in the turbidity of the shearing fluid, and contrasting the observed changes against the calculated shear stress at the fluid-substrate boundary. The Gust Chamber has been applied in both fluvial and marine settings [37, 41, 42, 43], however, despite its portability, it is an ex-situ device designed to be used on extracted sediment cores, and thus risks measuring a critical shear stress that is not representative of the in-situ erodibility of the substrate. The instrument that we have developed is mechanically most similar to a Gust Chamber in that it exerts a horizontally applied fluid shear stress on the substrate using a rotating blade to shear the fluid which, in turn, shears the substrate. However, what distinguishes our new instrument from the Gust chamber is that our instrument is specifically meant to measure sediment erodibility in-situ. We have employed a more simplified design that allows the user to implement the device with ease in the field.

\section{Device Design}

\subsection{Device Overview}

The device, seen in Figure 3, uses an impeller to generate a fluid shear stress within a chamber with an open bottom that is placed on a substrate. The impeller rotation rate $(\Omega)$ is controlled by an microcontroller (Arduino Uno) and a motor driver that controls the speed of a DC motor. The DC motor is attached to a chuck and gear box that allows for easy attachment of the impeller shaft. For the prototype design, a drill with a brushed DC motor is used. An optical encoder, attached to the rear shaft, is used to measure the motor speed. By controlling the speed of the impeller, we are able to directly control the fluid shear stress exerted on the substrate. To detect the onset of erosion of the substrate, the turbidity of the eroding fluid is monitored using turbidity sensors. Prior to the initiation of the impeller rotation, a baseline turbidity is measured. As the shearing process occurs, the turbidity is continuously monitored and the onset of erosion is detected by noting a rapid increase in the turbidity of the shearing fluid, relative to the initial turbidity. The device is meant to output two values at each sampling increment that can be selected by the user: the motor RPM, and the turbidity sensor readings. These data can either be directly output to a laptop via serial communication, or saved to a data storage device attached to the microcontroller. Laboratory calibration is required to convert the motor RPM to a fluid shear stress value. This method can be employed on a wide range of river bed and bank materials, from clay-rich mud through sand and medium-sized gravel (with slight modifications of the optical monitoring technique on the coarser end). Currently this device is at the stage where it can only be used in shallow, wadeable rivers, however, with slight modifications it will be fully waterproofed and deployable at depth in a larger river.

\subsection{Prototype Design and Parts List}

They key components of a Mudbuster are: a motor that drives an impeller, an encoder to record the motor speed, an optical sensor to detect the onset of erosion, and a microcontroller that controls the device. The design of the impeller will dictate the degree of turbulent shear that will be produced for a given RPM. The relationship between motor speed and voltage is indirect; as consequence, RPM can controlled in a relative manner through voltage, but a fixed calibration between the two is not possible. For this reason we recommended the usage of the microcontroller equipped with a motor driver to control the voltage supplied to the motor, and a rotary encoder to directly measure the motor speed. The optical sensors used to detect the onset of erosion of cohesive sediment are turbidity sensors which measure the light transmittance through the fluid, which they report as a voltage output by the sensor. As the increased presence of the suspended particles in the fluid increases the amount of light scattered, increases in turbidity will result in lower voltage outputs by the sensors. This detection method is only applicable to cohesive sediments, for which the threshold of suspension and the threshold of entrainnment are the same. For non-cohesive substrates where bed load occurs above the entrainment threshold, turbidity sensors cannot be utilized — or, at least, our current design cannot detect bed load using turbidity sensors. Here we use a camera to detect the onset of transport using image decorrelation analysis. This method could also work for cohesive substrates as well; however, it is more expensive and data storage intensive, and may be challenging to implement in waters with high ambient turbidity. The entire device is controlled using a microcontroller that can either be controlled by a laptop, a smartphone via a bluetooth connection, or using a button to run a series of pre-set commands. The design from the prototype is run using the Arduino software. Table 1 lists the parts necessary to build a version of this instrument, and the version of the part that was used in the prototype design. Figure 2 outlines the general form of the Mudbuster with its key components. The prototype design of the Mudbuster is approximately $1.7 \mathrm{~m}$ long and approximately $8 \mathrm{~kg}$ to enable use in a field environment without requiring full waterproofing of the motor and other electronics. As a result, this prototype design is larger than is ultimately necessary. Future directions include the development of a smaller, lighter, and fully waterproofed design. 
Table 1: Components required to build a Mudbuster and the versions used in the prototype design.

\begin{tabular}{|l|l|}
\hline Components & Prototype Part \\
\hline DC Motor & $\begin{array}{l}\text { Dewalt 20 Volt MAX Lithium Ion Cordless drill motor (chuck and gear } \\
\text { box included) }\end{array}$ \\
\hline Battery & Battery from Dewalt 20 Volt MAX Lithium Ion Cordless drill motor \\
\hline Rotary Encoder & $\begin{array}{l}\text { Signswise 600p/r Incremental Rotary Encoder Dc5-24v Wide Voltage } \\
\text { Power Supply 6mm Shaft }\end{array}$ \\
\hline Microcontroller & Arduino Uno \\
\hline Motor Driver & Cytron 10A DC Motor Driver Arduino Shield \\
\hline SD Card Interface & $\begin{array}{l}\text { HiLetgo Stackable SD Card and TF Card Shield for Arduino UNO R3 } \\
\text { Arduino Mega 2560 + 16GB SD Card }\end{array}$ \\
\hline Turbidity Sensor & Gravity Analog Turbidity Sensor \\
\hline Bluetooth Connector & $\begin{array}{l}\text { KEDSUM Upgraded HC-06 Serial Slave Module, Wireless RF } \\
\text { Transceiver Module with DuPont Cable }\end{array}$ \\
\hline Impeller & Vacuum cleaner blade \\
\hline Chamber & Acrylic cylinder (17.78cm diameter) \\
\hline
\end{tabular}

\subsection{Calibration of boundary stress}

The purpose of the Mudbuster is to determine the boundary stress, $\tau_{b}$, associated with the entrainment threshold of a given substrate, $\tau_{c}$. Do do this, a series of empirical calibration steps must completed in order to convert between the impeller rotation rate and fluid shear stress. Given that the Mudbuster's flow configuration is a rotational shear flow imposed by an impeller, we cannot use the Law of the Wall to solve for $\tau_{b}$, as we could in a logarithmic velocity profile that is typically seen in open channel flows. The near-bed Reynolds stress, $\tau_{i j}^{\prime}$, is often used as a proxy for the boundary stress in studies of sediment transport [44], and is defined as:

$$
\tau_{i j}^{\prime}=-\rho \overline{u^{\prime} w^{\prime}}
$$

where $u^{\prime}$ and $w^{\prime}$ are the deviatoric velocity components in the horizontal and vertical directions, respectively, the overbar here and elsewhere denotes averaging over a sufficient time period to achieve stationarity, and $\rho$ is fluid density. Deviatoric velocities are computed from measurements of instantaneous velocity components $u$ and $w$ as:

$$
u=\bar{u}+u^{\prime} ; w=\bar{w}+w^{\prime}
$$

A Nortex Vectrono Acoustic Doppler Velocimeter (ADV) was used to determine the deviatoric velocity components of the flow. The ADV measured times series of instantaneous flow velocity at a frequency of $200 \mathrm{~Hz}$. These measurements were averaged over 1 second windows to compute $\tau_{i j}^{\prime}$.

Figure 4 shows a calibration curve at an elevation of $z=0.5 \mathrm{~cm}$ above the bed. The data presented in Figure 4 are the result of five different experimental runs, demonstrating that, for our prototype design, the relationship between Reynolds stress and impeller RPM is both smooth and reproducible up to approximately 200 RPMs. The data follow a $2^{\text {nd }}$ order polynomial fit, as is expected on dimensional grounds $\left(\tau \sim \rho u^{2}\right)$ and also from a Prandtl-mixing length eddy-viscosity model $\tau_{i j}^{\prime}=\rho(\kappa z d \bar{u} / d z)^{2}$ where $d \bar{u} / d z \propto \Omega$ and $\kappa=0.41$ is von Karman's constant.

Given the constraints of the experimental setup, the closest point to the bed where flow velocity could be measured using an ADV was $z=0.5 \mathrm{~cm}$ above the bed. As such, it is not possible to directly measure the boundary Reynolds stress. Previous studies in open channel flows, including natural rivers, have found that the Reynolds stress increases with decreasing distance to the bed. These studies estimate the boundary Reynolds stress, $\tau_{b, R}$, as the Reynolds stress at the bed, i.e. $\tau_{b, R}=\tau_{i j, z=0}^{\prime}$, by fitting a linear profile to the region of increasing $\tau_{i j}^{\prime}$ and extrapolating the fit to the bed $(z=0)[44,45,46,47]$. We follow that method here. By taking a vertical profile of Reynolds stress in the chamber for a given impeller RPM (shown in Figure 5), we linearly extrapolate the trend observed in the points closest to the bed to approximate the boundary Reynolds stress for a given impeller RPM. To account for the effects of boundary roughnesses across a range of substrates, we collected vertical profiles of Reynolds stress above a smooth bed made of plumber's putty, a slightly rougher bed made of $500 \mu \mathrm{m}$ sand glued to a surface, and a rougher bed of $0.75 \mathrm{~cm}$ gravel glued to a surface.

As shown in Figure 5, the roughness of the boundary influences the vertical profile of Reynolds stress, and thus the calculation of the boundary Reynolds stress, introducing an unknown error in estimating the boundary stress based on impeller RPM. As it is infeasible to take velocity measurements during field deployment, it is necessary to quantify the error. We examine the ratio of the extrapolated boundary stress $\tau_{b, R}^{\prime}$ to the Reynolds stress at $0.5 \mathrm{~cm}$ above the bed, $\tau_{i j, 0.5 \mathrm{~cm}}^{\prime}$ (Fig. 7). While the relation is 


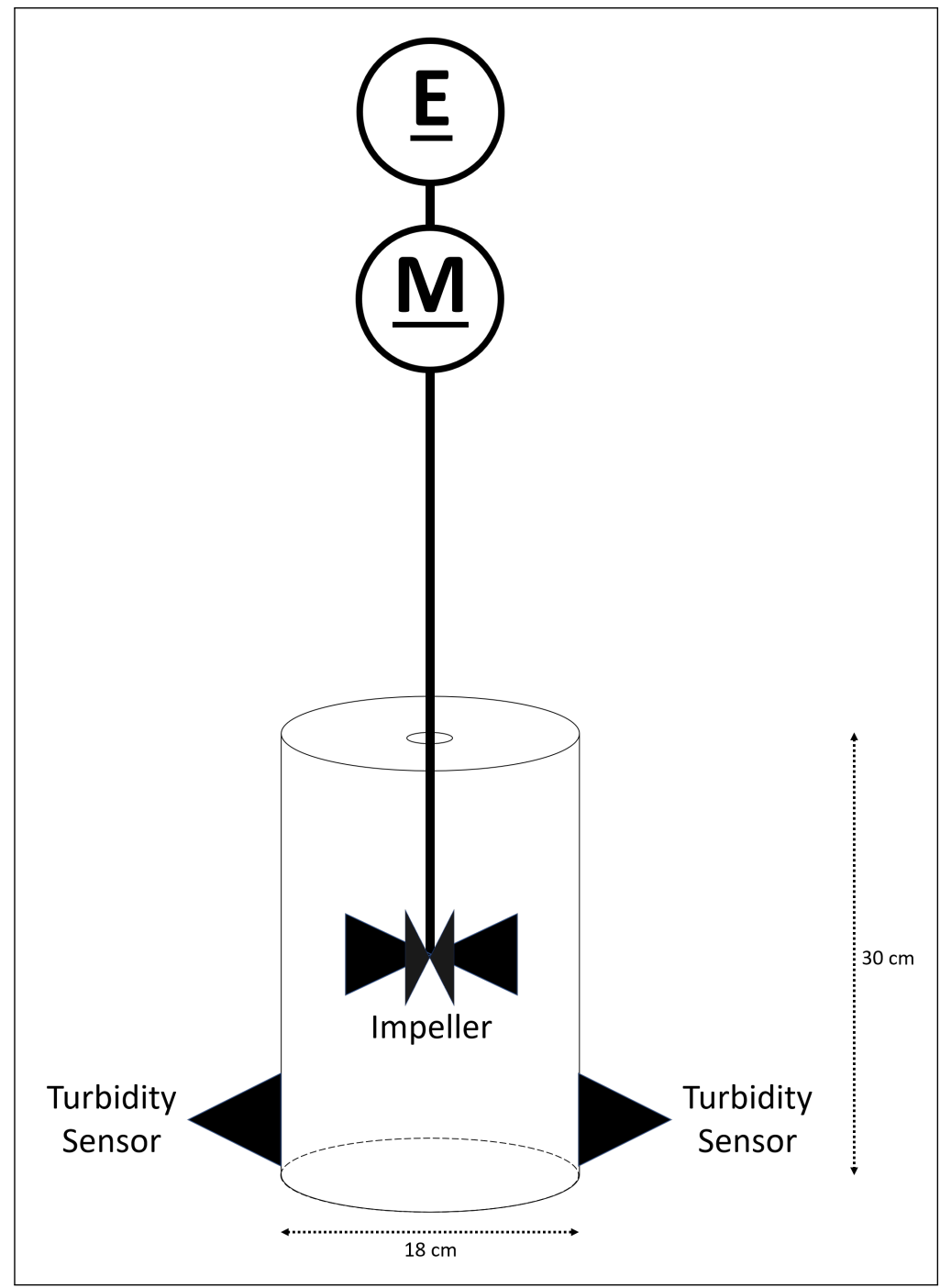

Figure 2: Schematic design for the Mudbuster. A DC motor $(\underline{\mathrm{M}})$ drives an impeller positioned in an open-bottom chamber. A rotary encoder $(\underline{E})$ is attached to the motor to measure motor speed. Multiple turbidity sensors are placed close to the bottom of the chamber to detect to onset of erosion of the sheared substrate.

different for different substrates, they converge to a similar value (or a small range of values) for Reynolds stresses larger than 0.5 $\mathrm{Pa}$. Given that this instrument is designed for use in the field where the additional variability of a natural environment can make exact determination of the boundary roughness difficult to impossible (i.e. roughness changes from small roots, soil aggregates, heterogeneous grain size mixtures, etc.), we recommend using an averaged value for data collected in a field environment. For practical purposes, the boundary stress may be considered to be roughly 1.4 times the Reynolds stress measured at $0.5 \mathrm{~cm}$ above the bed, i.e., $\tau_{b, R}^{\prime}=\alpha \tau_{i j, 0.5 \mathrm{~cm}}^{\prime}$ where $\alpha \approx 1.4$.

In order for the $\tau_{b, R}$ values to be meaningful with regards questions of sediment transport or morphology in natural environments, it is necessary to determine what value our measured $\tau_{b, R}$ value would correspond to in an open channel flow. Typically, boundary stress in rivers is measured either using a depth-slope product ( $\tau=\rho g H S$, where $H$ is the flow depth, $S$ is the water surface slope, and $g$ is the acceleration due to gravity), or fitting a profile of time-averaged streamwise velocity with a log-law $\left(\bar{u}(z)=u_{*} \ln \left(z / z_{0}\right) / \kappa\right.$, where $z_{0}$ is the roughness height, and $u^{*}$ is the shear velocity related to $\tau_{b}$ by $\tau_{b}=\rho u_{*}^{2}$ ). Since both rely on normal flow assumptions, we call this stress $\tau_{b, n}$. Previous studies have reported consistent discrepancies between boundary stresses determined using these methods, and those determined from the boundary Reynolds stress method used above; i.e., $\tau_{b, n}=\beta \tau_{b, R}^{\prime}$. Although reported values can vary significantly, a representative value of $\beta=3.9$ was found to describe most data - field and laboratory settings — reasonably well [44]. We note that Biron et al. [44] conducted experiments in a laboratory flume with open-channel flow conditions; their measured ratio $\alpha=1.6$, was similar to ours, indicating that the Reynolds stress extrapolation in our helical shear cell is similar to what is observed in normal flow conditions. Accordingly, for comparison of stresses determined using the 


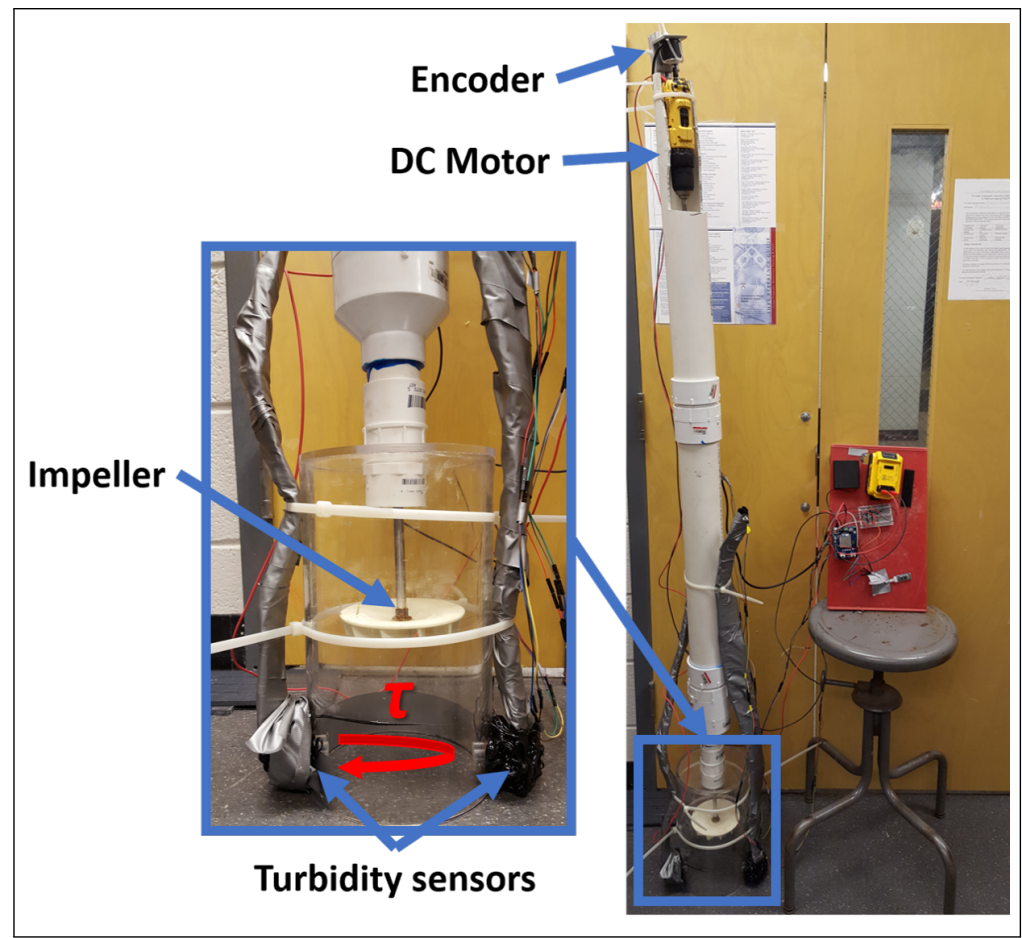

Figure 3: The prototype design of the Mudbuster as of April 2019.

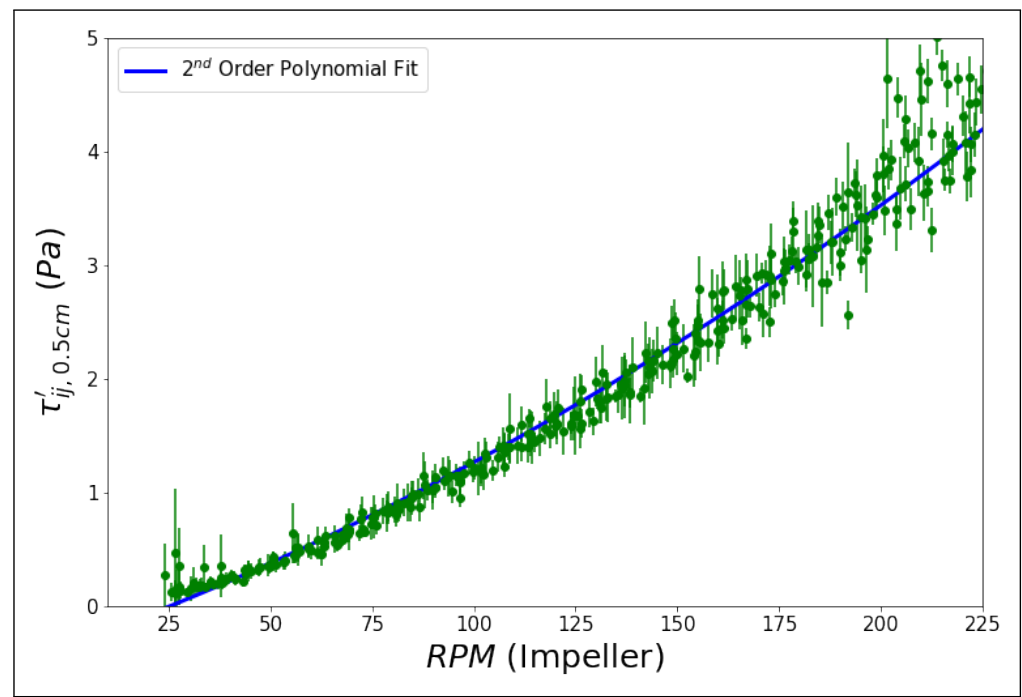

Figure 4: Measured Reynolds stress increases with impeller RPM $(\Omega)$ at $z=0.5 \mathrm{~cm}$ above the bed. Line of best fit is a $2^{\text {nd }}$ order polynomial, $\tau_{i j, 0.5 \mathrm{~cm}}^{\prime}=3.24 e-05 \Omega^{2}+0.013 \Omega-0.347$. Error bars represent \pm 1 standard deviation around sampled value at each point.

Mudbuster to boundary stresses estimated using normal flow approximations, we recommend the approximation $\tau_{b, n} \approx 4 \tau_{b, R}^{\prime}$ for most conditions.

\subsection{Determination of Initiation of Motion}

Two optical methods were used for determining the threshold of motion. The first method used image analysis to calculate the decorellation of a time series of images of the bed sediment as shear was increased. As mentioned above, turbidity sensors will not work for noncohesive sediments; we tested the image technique for noncohesive and cohesive sediments for completeness. A camera took images at a rate significantly higher than the rate at which stress was increased. Our calibration used a Nikon DSLR sampling at $1 \mathrm{~Hz}$ to take a series of oblique photographs of the bed as the shear stress was gradually increased over 10-second 

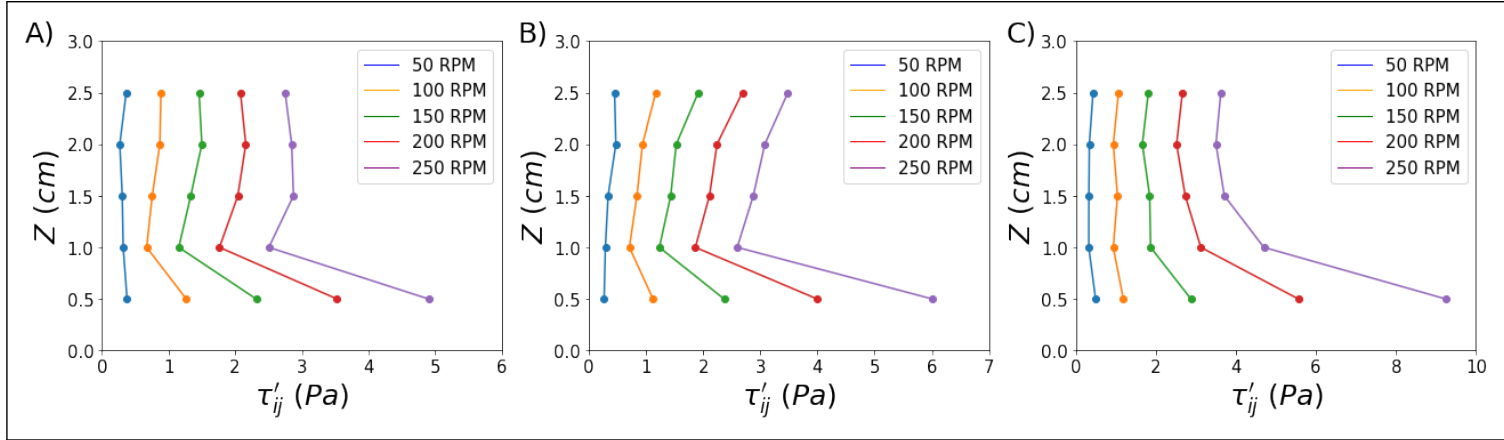

Figure 5: Example vertical profiles of Reynolds stress over a A) clay, B) sand $\left(D_{50}=500 \mu \mathrm{m}\right)$, and C) gravel $\left(D_{50}=0.75 \mathrm{~cm}\right)$ boundary. The region of increasing Reynolds stress on approach to the bed is used to linearly extrapolate to the boundary $z=0$. Line color indicates impeller rotation rate. Setup described in Fig. 6.

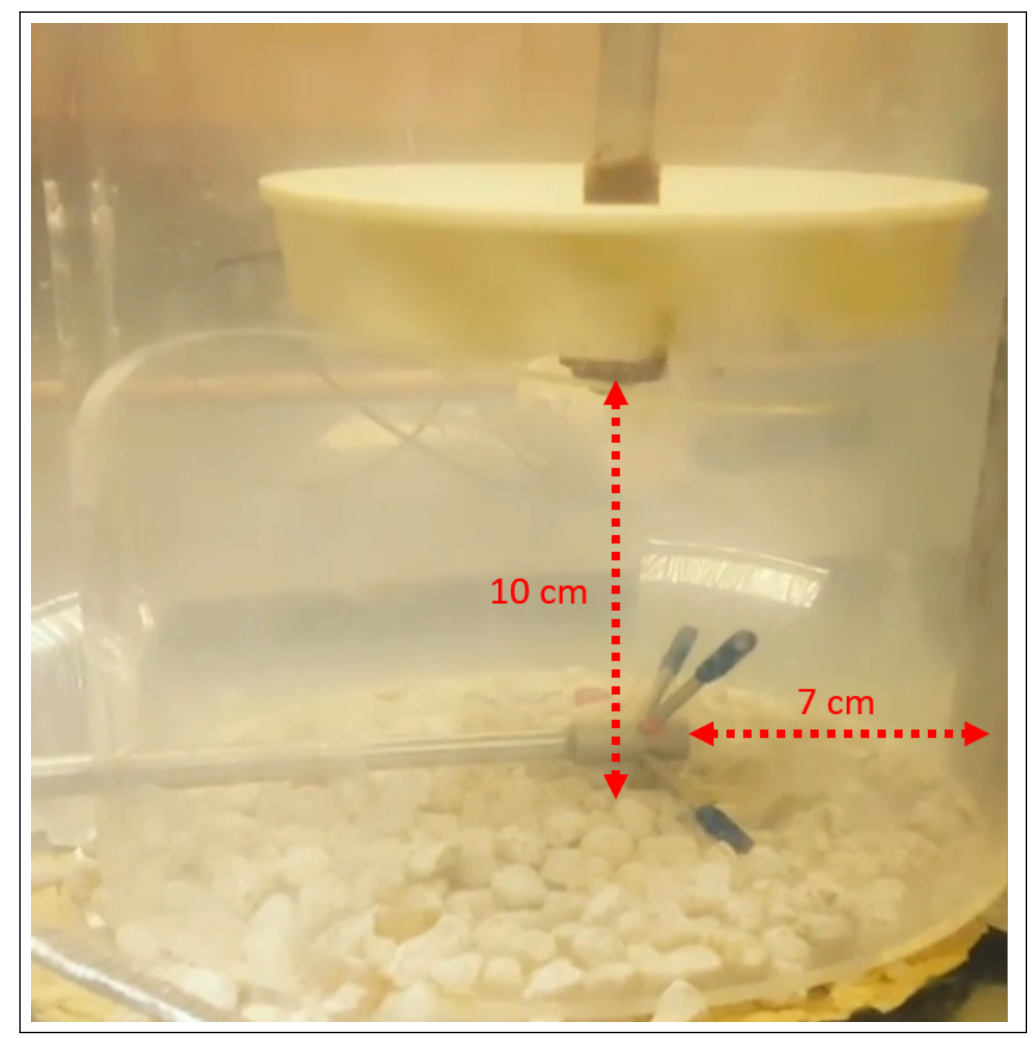

Figure 6: ADV inserted horizontally into the flow field for calibration and positions such that the ADV sampling volume location is at the distance from wall that corresponds to point of maximum stress for the configuration. For the prototype design, this was found to be approximately $7 \mathrm{~cm}$ from the boundary. For the prototype design, the impeller was positioned $10 \mathrm{~cm}$ above the boundary. Data were sampled at $0.5 \mathrm{~cm}$ increments vertically to produce RPM-stress calibration curves (e.g. Fig. 4) at each elevation above the boundary.

periods per increment of voltage supplied to the motor. The bed was remade and water replaced after each experimental run. Figure 8 illustrates the experimental setup.

The python image processing package scikit-image was then used to cross-correlate each image against an image of the substrate in ambient water. This allowed us to produce a time series of error that was normalized against a background error calculated from a time series taken in ambient water, producing a time series of normalized error, $\hat{E}$, that can be compared between multiple trials. Figure 9 shows example data from experiments that were run for Clay, Mud (50\% clay, 50\% sand mixture), Sand $\left(D_{50}=500 \mu \mathrm{m}\right)$, Gravel $\left(D_{50}=0.75 \mathrm{~cm}\right)$, and Cobbles $\left(D_{50}=5 \mathrm{~cm}\right) . \hat{E}$ is shown to initially remain approximately equal to 1 before a threshold stress is reached, at which point $\hat{E}$ rapidly increases (Fig. 9). We consider $\hat{E}=1.2$ to be a point of significant image decorrelation, and thus the corresponding $\tau_{i j, 0.5 \mathrm{~cm}}^{\prime}=\tau_{c}$, after which the change in $\hat{E}$ is most rapid for any additional increase in stress. The least 


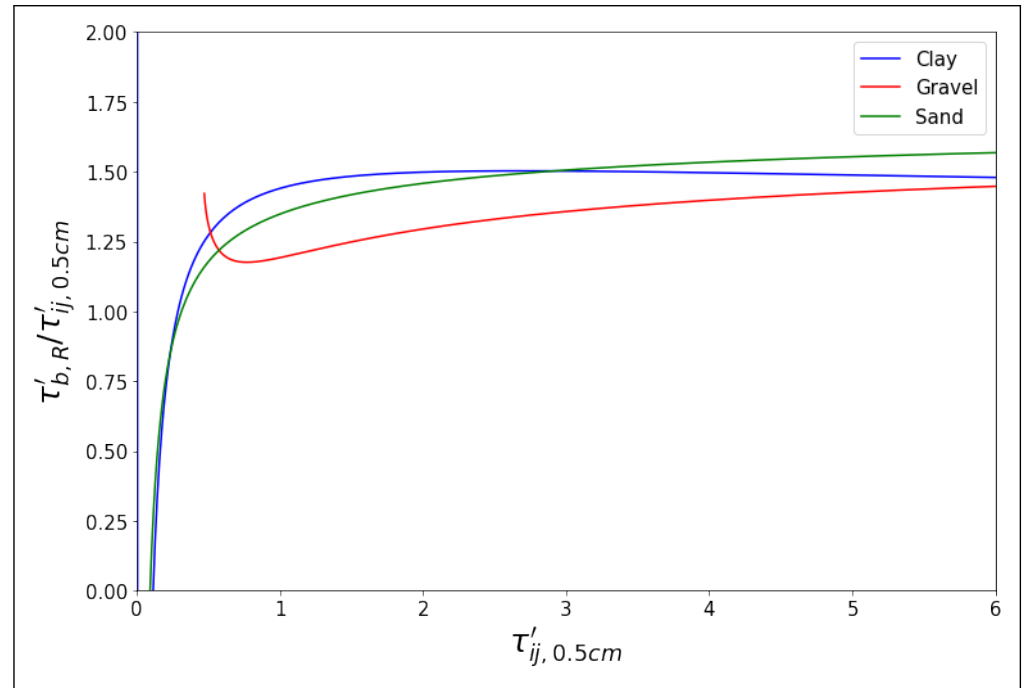

Figure 7: Calibration curve for conversion from measured Reynolds stress at $z=0.5 \mathrm{~cm}$ to boundary Reynolds stress $(z=0)$ for different boundary roughness conditions. Further tests were not conducted over rougher substrates because the size of individual grains would have been comparable to the sampling area of the ADV, and thus not necessarily representative of flow over the boundary as a whole.

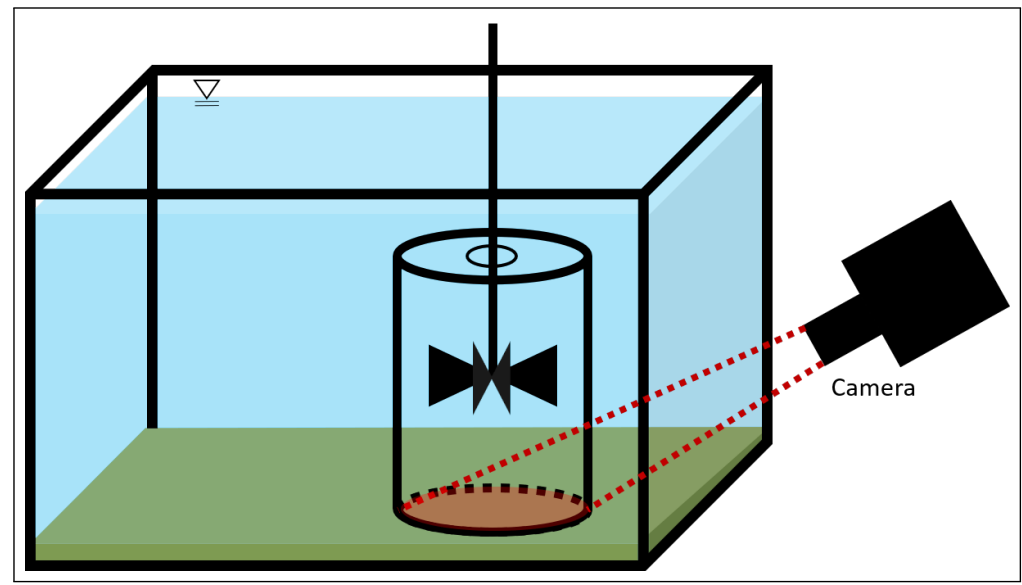

Figure 8: Schematic of experimental setup to determination of the threshold of motion from image decorrelation analysis. Camera is focused on sheared portion of the bed and collects time series of bed images as shear is systematically increased.

consistent data are for the cobbles (diameter $=7 \mathrm{~cm}$ ), for which the transport was much more intermittent — likely due to their relatively large size and hence small number of particles in the field of view.

We remind the reader of the potential challenges of using an image-based technique in the field. According, we also tested turbidity sensors for detecting the entrainment threshold of cohesive clay sediment beds comprised of kaolin clay with $D_{50}=3 \mu \mathrm{m}$. The turbidity sensors used in the prototype design are photodiodes that measure changes in the light scattering in a fluid due to suspended particles and record the turbidity reading as a voltage $\hat{V}$. As the turbidity of the water increases, the more light is scattered by the increasing concentration of suspended particles, resulting in a lower voltage reading. For the prototype design, we used two sensors for redundancy. Upon the exceedance of $\tau_{c}$ for a cohesive substrate, turbidity sensors will show a rapid decrease in voltage relative to an ambient voltage measurement taken prior to shearing - comparable to the previously discussed calculation of $\hat{E}$. Figure 10 provides an example of the use of turbidity sensors to detect the $\tau_{c}$ of clay, and demonstrates the rapid falloff in $\hat{V}$ after $\tau_{c}$ has been exceeded at a $\tau_{i j, 0.5 \mathrm{~cm}}^{\prime}$. The determined value for $\tau_{c}$ is similar to that measured from the image decorrelation method within a factor of approximately $10 \%$.

As turbidity sensors can only detect changes in the concentration of suspended sediment, their usage to detect the threshold of motion is primarily useful for cohesive substrates, for which the $\tau_{c}$ is strong enough to entrain particles into suspension (i.e. bedload transport does not exist). In a field setting, it is possible that the entrainment of sand or gravel might result in the simultaneous suspension of fine sediment attached to the coarser grains, allowing $\tau_{c}$ to be detected for non-cohesive sediment using turbidity sensors. 


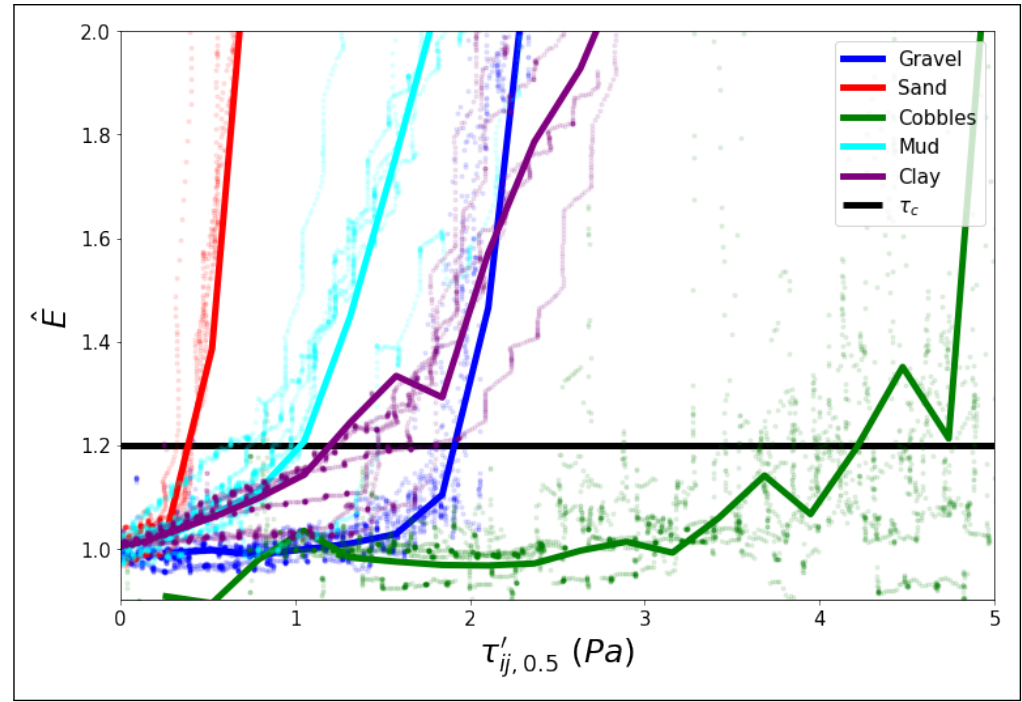

Figure 9: Average decoreelation $\hat{E}$ for each substrate as a function of increasing $\tau_{i j, 0.5 \mathrm{~cm}}^{\prime}$. Clay, Mud (50\% clay, $50 \%$ sand mixture), Sand $\left(D_{50}=500 \mu \mathrm{m}\right)$, Gravel $\left(D_{50}=0.75 \mathrm{~cm}\right)$, and Cobbles $\left(D_{50}=5 \mathrm{~cm}\right)$

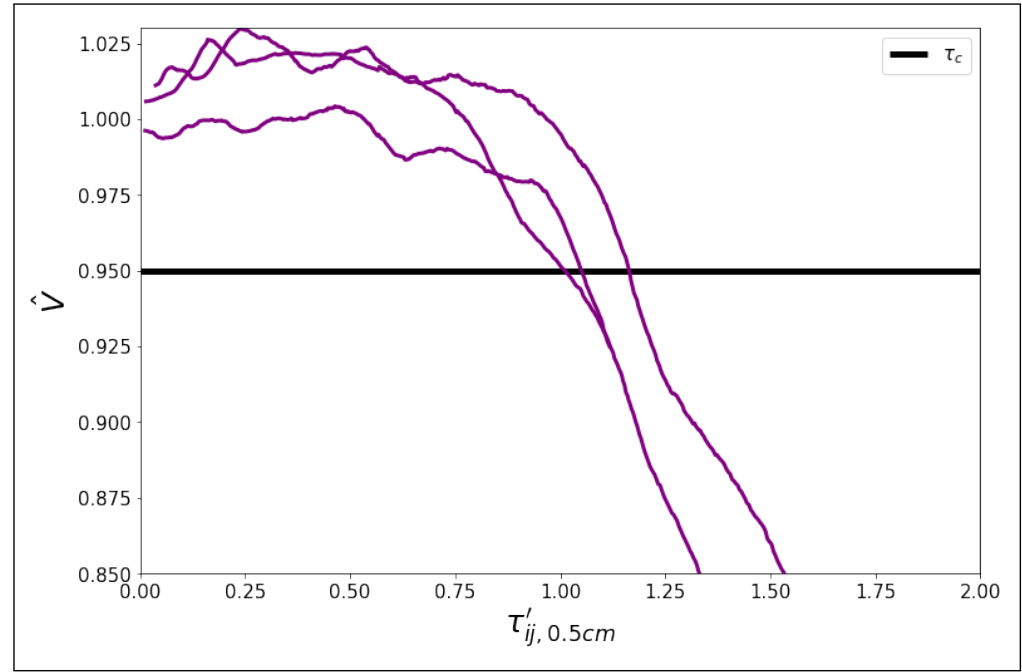

Figure 10: Example threshold of motion detection using turbidity sensors for clay. Rapid falloff in $\hat{V}$ occurs after a certain $\tau_{c}$ has been exceeded.

\section{Demonstration of Capability}

Using the described calibration process, we have used the instrument to explore the change in $\tau_{c}$ of a fine-grained substrate as a function of clay percentage by mass. Kaolinite clay was mixed with $500 \mu \mathrm{m}$ sand in a drum and with $10 \%$ water by mass. The mixture was then tamped down at the base of a tank and water was added and cycled through at a low flow rate until the water was clear. This mild "strain-hardening" process removed any surficial sediment that was not adhered to the bed and is comparable to the natural environment, as all cohesive sediment in a fluvial environment is continuously subjected to shear from base flow. Identical to the experimental runs described above, the bed was remade and water replaced after each experimental run. As shown in Figure 11, clay percentage has a sigmoidal effect on the $\tau_{c}$ of sand-clay mixtures, as clay has a minimal effect of the bulk strength of a mixture until the pore space between the larger sand grains is filled with clay. This result is consistent with studies of the effect of clay content on the incipient motion of granular materials [6,5]. While the trend is consistent with other empirical studies, the exact values are not expected to be representative of the $\tau_{c}$ for arbitrary mud mixtures given variations in grain size and composition. Also, this significant change in $\tau_{c}$ with the addition of clay is not expected to the replicated for larger, gravel-sized grains where interstitial clays do significantly influence entrainment [6].

We further used our instrument to test the $\tau_{c}$ of non-cohesive substrates to provide a comparison between $\tau_{c}$ as measured by our instrument and a predicted $\tau_{c}$ from the Shields curve [48]. Using image decorrelation analysis to identify the threshold of motion, a stress-dependent $\alpha$ value determined from our calibration curve (Fig. 7), and a $\beta=3.9$ value, we are able to determine the $\tau_{c}$ for 


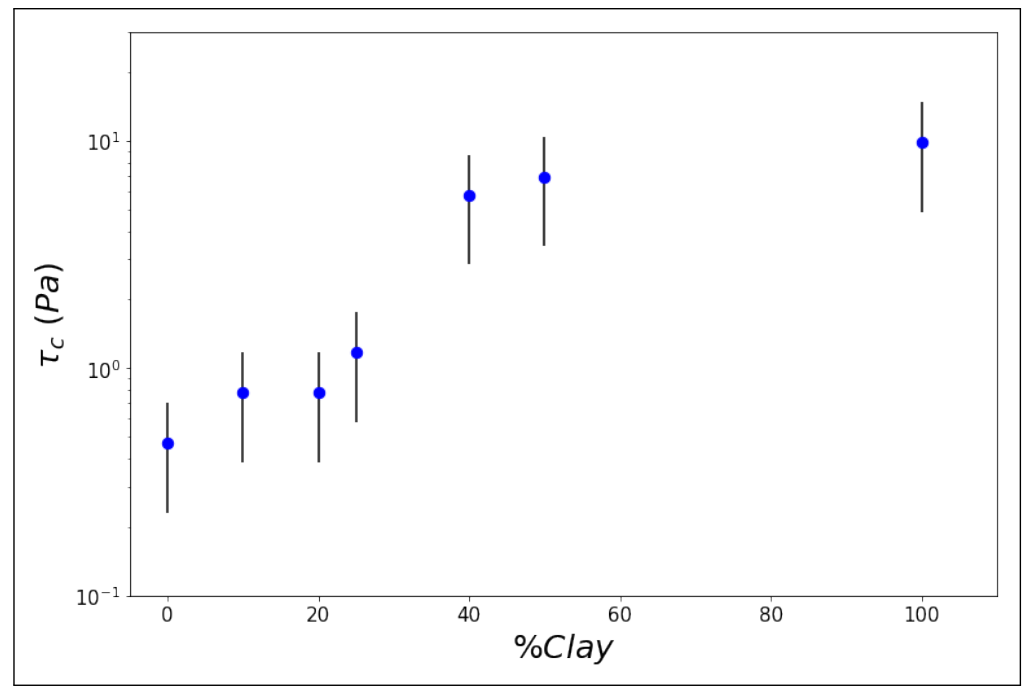

Figure 11: Experimentally determined $\tau_{c}$ for sand-clay mixtures with varying clay content. Reported values are for $\tau_{c}=\tau_{b, n}$. All mixtures given similar mixing and compaction treatment prior to shearing. Error bars indicate \pm 1 standard deviation.

each substrate, where $\tau_{c}$ is comparable to the boundary stress exerted by a normal flow, $\tau_{b, n}$. Figure 12 shows that for non-cohesive sediments $\left(D_{50} \geq 0.0005 \mathrm{~m}\right)$, our instrument predicts a $\tau_{c}$ value similar to what would be expected from the Shields curve. This is further indicative that, at the grain scale, the helical flow created by the impeller in the chamber is similar to the normal flow conditions in flumes/channels. For $D_{50}<500 \mu \mathrm{m}$, the grain size is representative of an average grain size of the sand and clay in the mixture, weighted by percent mass. While this is not an accurate representation of $D_{50}$, it is indicative of a systematic deviation away from the predicted $\tau_{c}$ from the Shields curve as interparticle cohesion begins to take effect. As the Shields curve was developed for non-cohesive sediment, the deviation away from the Shields curve as clay particles are introduced into the substrate is expected.

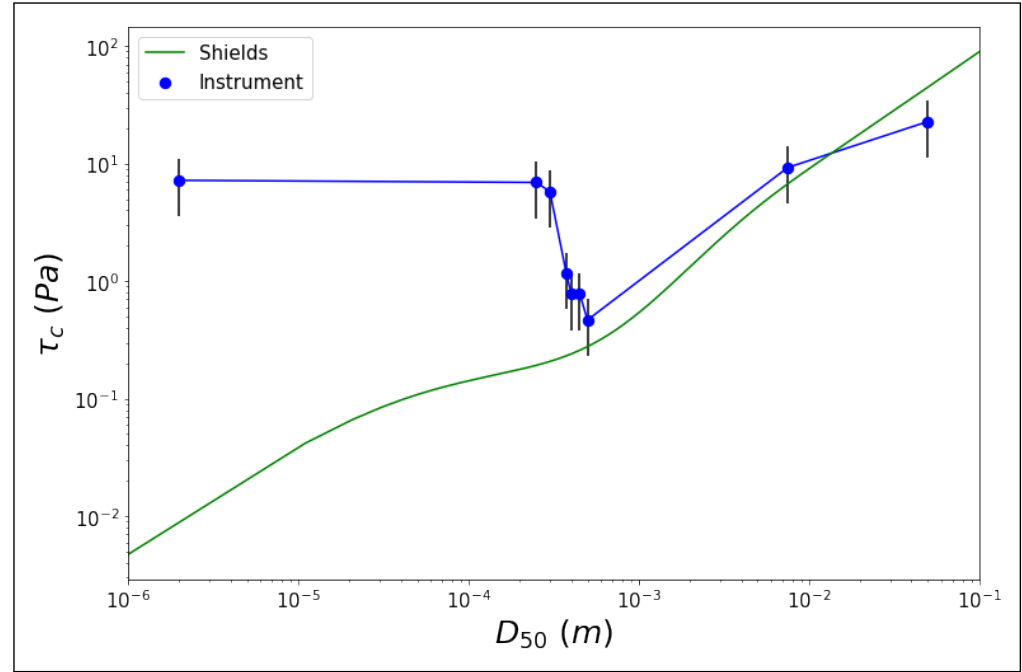

Figure 12: $\tau_{c}$ as a function of grain size as measured by the instrument. Green line is the dimensional Shields curve, back calculated from [48] for comparison. Reported values are for $\tau_{c}=\tau_{b, n}$. For $D_{50}<500 \mu \mathrm{m}$, the reported $D_{50}$ is representative of an average grain size of the sand and clay in the mixture, weighted by percent mass.

\section{Field Testing}

While this device can be controlled using a laptop, for the sake of convenience and portability during field implementation, we recommend using an SD card to store the collected data output by the turbidity sensors and the encoder. To operate the instrument in the field, we recommend using a bluetooth connection to control the device from a smartphone, or building a button/switch to initiate a shearing protocol that will run to conclusion after each press. 
To test the Mudbuster in the field, we conducted tests on the Mullica River, a river with banks composed of cohesive mud in the New Jersey coastal plain. The open-bottom chamber was placed up against the toe of the river bank and a smart phone was used to control the device (Fig. 13A). In the more complicated, heterogeneous field setting, the falloff in $\hat{E}$ is not consistent in form, however using a 2-D histogram, we can determine a point of significant divergence away from the initial condition of $\hat{V} \approx 1$ (Fig. 13B). Preliminary data from the field show that the Mullica's cohesive bank material has a critical stress of $\tau_{c} \approx 4 \mathrm{~Pa}$. This value is within an expected range of $\tau_{c}$ values for consolidated cohesive sediment in natural settings [16, 33, 28].

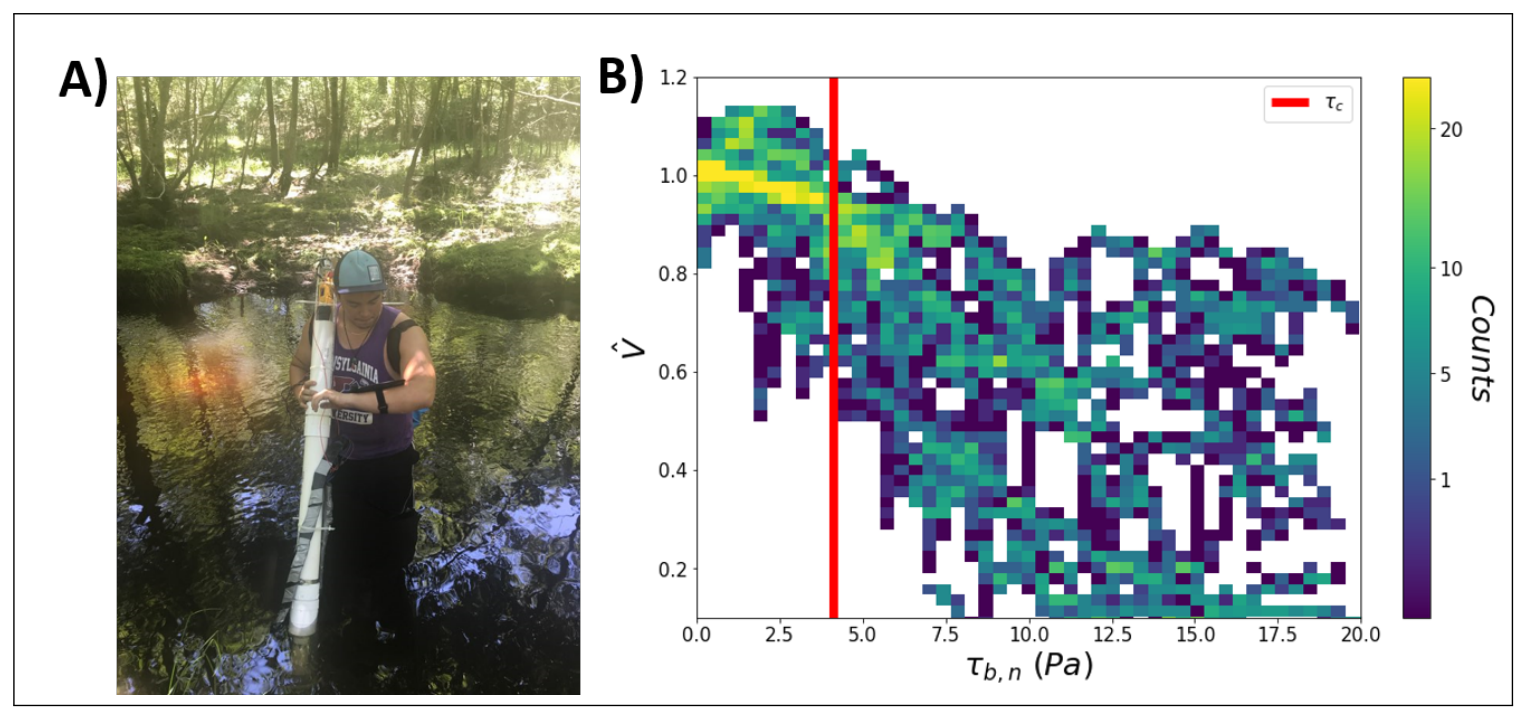

Figure 13: A) Deployment of the Mudbuster in the field to test the erodibility of a cohesive river bank. The instrument developed at the time of this manuscript's publication is currently only able to be deployed in wadeable streams, however further developments will include full waterproofing that will allow the instrument to be deployed at depth. B) 2-D histogram showing $\hat{V}$ divergence from initial condition $\hat{V}=1$ with increasing $\tau_{b, n}$. Warmer colors indicate frequency of $\hat{V}$ values measured for a given $\tau_{b, n}$ across multiple measurements. Red line indicated approximation of $\tau_{c}$. Error bars are indicative of \pm 1 standard deviation.

\section{Discussion And Conclusions}

We have developed an instrument that is capable of determining $\tau_{c}$ for granular substrates in-situ. This instrument consists of an impeller in an open-bottom chamber that is placed on a granular substrate, fully submerged in water. The speed of the impeller is gradually increased using a microcontroller, thereby increasing the fluid shear exerted on the substrate. The onset of erosion of the substrate is detected using optical sensors, either through image decorrelation analysis, or, as recommended for field use on cohesive substrates, the use of turbidity sensors to detect rapid changes in the amount of suspended material in the water. The prototype design utilizes a motor and impeller combination that is capable of reproducibly inducing a $\tau_{b, n}$ up to approximately 22.5 Pa. We have carried out and described the necessary laboratory calibration steps to develop a conversion between a directly measured $\tau_{i j}^{\prime}$ using an $\mathrm{ADV}$, to $\tau_{b, R}^{\prime}$, and finally to $\tau_{b, n}^{\prime}$ in order to provide an estimation for boundary stress that is comparable to the more commonly used depth-slope product or log-law estimations. We have demonstrated two different optically-based methodologies for detecting $\tau_{c}$ for a range of substrate. Using image decorrelation analysis in a laboratory setting we demonstrate the Mudbuster's capability to determine $\tau_{c}$ for a range of cohesive and non-cohesive substrates, ranging from pure clay to large gravel. We compare our measured $\tau_{c}$ values to predicted $\tau_{c}$ values from the Shields curve and find similar values for non-cohesive sediment, and an expected significant deviation away from the Shields curve as cohesion takes effect at smaller grain sizes. The other detection method utilizes turbidity sensors and has been validated in the laboratory and tested on natural, cohesive river banks.

The in-situ measurement of $\tau_{c}$ for sediment, particularly cohesive sediment, is a critical component for field-based morphodynamic, geotechnical, environmental restoration, and landscape management studies. The Mudbuster provides a cheap, portable, and robust method for estimating river bank and bed sediment erosion criteria, which can subsequently allow the user to determine either the controlling parameters of, or variables dependent on, $\tau_{c}$. At its current state, the Mudbuster is only capable on being deployed in wadeable channels, however future developments include miniaturization and full waterproofing to allow for submerged deployment in deeper fluvial and marine environments. 


\section{ACKNOWLEDGEMENTS}

We thank Feifei Qian, Sonia Roberts, and Larry Galloway for their advice relating to the construction and wiring of the Mudbuster. Operating code and recommended Arduino pin assignments are available in the Supplemental Material. The research was sponsored by the Army Research Laboratory and was accomplished under grant number W911-NF-16-1-0290.

\section{REFERENCES}

[1] FAO FAO. Unesco soil map of the world, revised legend, with corrections and updates. World Soil Resources Report, 60:140, 1988.

[2] WD Kemper and RC Rosenau. Soil cohesion as affected by time and water content 1. Soil Science Society of America Journal, 48(5):1001-1006, 1984.

[3] Robert N Young and John B Southard. Erosion of fine-grained marine sediments: sea-floor and laboratory experiments. Geological Society of America Bulletin, 89(5):663-672, 1978.

[4] IN McCave. Erosion, transport and deposition of fine-grained marine sediments. Geological Society, London, Special Publications, 15(1):35-69, 1984.

[5] Fabien Ternat, Patrick Boyer, F Anselmet, and M Amielh. Erosion threshold of saturated natural cohesive sediments: Modeling and experiments. Water resources research, 44(11), 2008.

[6] Umesh C Kothyari and Rajesh Kumar Jain. Influence of cohesion on the incipient motion condition of sediment mixtures. Water Resources Research, 44(4), 2008.

[7] Jason P Julian and Raymond Torres. Hydraulic erosion of cohesive riverbanks. Geomorphology, 76(1-2):193-206, 2006. doi: 10.1016/j.geomorph.2005.11.003.

[8] Eugen Meyer-Peter and R Müller. Formulas for bed-load transport. In IAHSR 2nd meeting, Stockholm, appendix 2. IAHR, 1948.

[9] Peter R Wilcock and Joanna C Crowe. Surface-based transport model for mixed-size sediment. Journal of Hydraulic Engineering, 129(2):120-128, 2003.

[10] Gary Parker. Surface-based bedload transport relation for gravel rivers. Journal of hydraulic research, 28(4):417-436, 1990.

[11] Gary Parker, Peter C Klingeman, and David G McLean. Bedload and size distribution in paved gravel-bed streams. Journal of the Hydraulics Division, 108(4):544-571, 1982.

[12] Emmanuel Partheniades. Erosion and deposition of cohesive soils. Journal of the Hydraulics Division, 91(1):105-139, 1965.

[13] Colin B Phillips and Douglas J Jerolmack. Self-organization of river channels as a critical filter on climate signals. Science, 352(6286):694-697, 2016. doi: 10.1126/science.aad3348.

[14] Gary Parker. Self-formed straight rivers with equilibrium banks and mobile bed. part 2. the gravel river. Journal of Fluid mechanics, 89(1):127-146, 1978. doi: 10.1017/S0022112078002505.

[15] Gary Parker, Y Shimizu, GV Wilkerson, Esther C Eke, Jorge D Abad, JW Lauer, Chris Paola, William E Dietrich, and VR Voller. A new framework for modeling the migration of meandering rivers. Earth Surface Processes and Landforms, 36 (1):70-86, 2011. doi: 10.1002/esp.2113.

[16] Candice R Constantine, Thomas Dunne, and Gregory J Hanson. Examining the physical meaning of the bank erosion coefficient used in meander migration modeling. Geomorphology, 106(3-4):242-252, 2009. doi: 10.1016/j.geomorph.2008. 11.002 .

[17] Daniel R Parsons, Robert J Schindler, Julie A Hope, Jonathan Malarkey, Jaco H Baas, Jeffrey Peakall, Andrew J Manning, Leiping Ye, Steve Simmons, David M Paterson, et al. The role of biophysical cohesion on subaqueous bed form size. Geophysical research letters, 43(4):1566-1573, 2016.

[18] Albert Shields. Application of similarity principles and turbulence research to bed-load movement. CalTech library, 1936.

[19] Ahmet Ozan Celik, Panayiotis Diplas, and Clint L Dancey. Instantaneous turbulent forces and impulse on a rough bed: Implications for initiation of bed material movement. Water Resources Research, 49(4):2213-2227, 2013.

[20] Panayiotis Diplas, Clint L Dancey, Ahmet O Celik, Manousos Valyrakis, Krista Greer, and Tanju Akar. The role of impulse on the initiation of particle movement under turbulent flow conditions. Science, 322(5902):717-720, 2008.

[21] Angel Monsalve, Elowyn M Yager, and Mark W Schmeeckle. Effects of bed forms and large protruding grains on nearbed flow hydraulics in low relative submergence conditions. Journal of Geophysical Research: Earth Surface, 122(10): 1845-1866, 2017.

[22] Athanasios N Papanicolaou, Mohamed Elhakeem, and Robert Hilldale. Secondary current effects on cohesive river bank erosion. Water Resources Research, 43(12), 2007. 
[23] EM Yager, JM Turowski, D Rickenmann, and BW McArdell. Sediment supply, grain protrusion, and bedload transport in mountain streams. Geophysical Research Letters, 39(10), 2012.

[24] Elowyn M Yager, WE Dietrich, James W Kirchner, and BW McArdell. Prediction of sediment transport in step-pool channels. Water Resources Research, 48(1), 2012.

[25] Claire C Masteller and Noah J Finnegan. Interplay between grain protrusion and sediment entrainment in an experimental flume. Journal of Geophysical Research: Earth Surface, 122(1):274-289, 2017.

[26] AN Papanicolaou, P Diplas, N Evaggelopoulos, and S Fotopoulos. Stochastic incipient motion criterion for spheres under various bed packing conditions. Journal of Hydraulic Engineering, 128(4):369-380, 2002.

[27] BP Warkentin and RN Yong. Shear strength of montmorillonite and kaolinite related to interparticle forces. In Clays and Clay Minerals, pages 210-218. Elsevier, 1962.

[28] John M Laflen, Robert Patrick Beasley, et al. Effects of compaction on critical tractive forces in cohesive soils. University of Missouri, College of Agriculture, Agricultural Experiment Station, 1960.

[29] Serena L Teasdale, Xuxu Wu, Leiping Ye, and Christopher R Hackney. 1.2. 4 the identification and extraction of extracellular polymeric substances (eps) from sediments. 2018.

[30] TM Wynn, MB Henderson, and DH Vaughan. Changes in streambank erodibility and critical shear stress due to subaerial processes along a headwater stream, southwestern virginia, usa. Geomorphology, 97(3-4):260-273, 2008.

[31] Theresa Wynn and Saied Mostaghimi. The effects of vegetation and soil type on streambank erosion, southwestern virginia, usa 1. JAWRA Journal of the American Water Resources Association, 42(1):69-82, 2006.

[32] GJ Hanson and KR Cook. Apparatus, test procedures, and analytical methods to measure soil erodibility in situ. Applied engineering in agriculture, 20(4):455, 2004. doi: 10.13031/2013.16492.

[33] GJ Hanson and Andrew Simon. Erodibility of cohesive streambeds in the loess area of the midwestern usa. Hydrological processes, 15(1):23-38, 2001. doi: 10.1002/hyp.149.

[34] Jochen Aberle, Vladimir Nikora, and Roy Walters. Effects of bed material properties on cohesive sediment erosion. Marine Geology, 207(1-4):83-93, 2004. doi: 10.1016/j.margeo.2004.03.012.

[35] Carl L Amos, J Grant, GR Daborn, and K Black. Sea carousel-a benthic, annular flume. Estuarine, Coastal and Shelf Science, 34(6):557-577, 1992.

[36] Kieran BJ Dunne and Douglas J Jerolmack. Evidence of, and a proposed explanation for, bimodal transport states in alluvial rivers. Earth Surface Dynamics, 6(3):583-594, 2018. doi: 10.5194/esurf-6-583-2018.

[37] Paul A Work and David H Schoellhamer. Measurements of erosion potential using gust chamber in yolo bypass near sacramento, california. Technical report, US Geological Survey, 2018.

[38] Maliheh Karamigolbaghi, Seyed Mohammad Ghaneeizad, Joseph F Atkinson, Sean J Bennett, and Robert R Wells. Critical assessment of jet erosion test methodologies for cohesive soil and sediment. Geomorphology, 295:529-536, 2017. doi: 10.1016/j.geomorph.2017.08.005.

[39] CL Amos, A Bergamasco, G Umgiesser, S Cappucci, D Cloutier, L DeNat, Mogens Flindt, M Bonardi, and S Cristante. The stability of tidal flats in venice lagoon - the results of in-situ measurements using two benthic, annular flumes. Journal of Marine Systems, 51(1-4):211-241, 2004.

[40] Giselher R Gust. Method of generating precisely-defined wall shearing stresses, November 27 1990. US Patent 4,973,165.

[41] Laurenz Thomsen and Giselher Gust. Sediment erosion thresholds and characteristics of resuspended aggregates on the western european continental margin. Deep Sea Research Part I: Oceanographic Research Papers, 47(10):1881-1897, 2000. doi: 10.1016/S0967-0637(00)00003-0.

[42] Brent A Law, PS Hill, TG Milligan, KJ Curran, PL Wiberg, and RA Wheatcroft. Size sorting of fine-grained sediments during erosion: results from the western gulf of lions. Continental Shelf Research, 28(15):1935-1946, 2008.

[43] BA Law, PS Hill, TG Milligan, and V Zions. Erodibility of aquaculture waste from different bottom substrates. Aquaculture Environment Interactions, 8:575-584, 2016.

[44] Pascale M Biron, Colleen Robson, Michel F Lapointe, and Susan J Gaskin. Comparing different methods of bed shear stress estimates in simple and complex flow fields. Earth Surface Processes and Landforms: The Journal of the British Geomorphological Research Group, 29(11):1403-1415, 2004.

[45] Vladimir Nikora and Derek Goring. Flow turbulence over fixed and weakly mobile gravel beds. Journal of Hydraulic Engineering, 126(9):679-690, 2000.

[46] T Song and YM Chiew. Turbulence measurement in nonuniform open-channel flow using acoustic doppler velocimeter (adv). Journal of Engineering Mechanics, 127(3):219-232, 2001.

[47] Xingwei Chen and Yee-Meng Chiew. Response of velocity and turbulence to sudden change of bed roughness in open-channel flow. Journal of Hydraulic Engineering, 129(1):35-43, 2003. 
[48] Leo C van Rijn. Initiation of motion and suspension; critical bed-shear stress for sand-mud mixtures. 2016. URL www. leovanrijn-sediment.com. 